\title{
Epidemiology and severity of non-alcoholic fatty liver disease in Greek tertiary liver centres
}

\author{
Savvoula Savvidou ${ }^{1}$, Margarita Papatheodoridi ${ }^{2}$, Konstantinos Zisimopoulos ${ }^{3}$, Kanellos Koustenis ${ }^{4}$, Dimitrios N Samonakis ${ }^{5}$, Theodoros \\ Voulgaris $^{2}$, Spilios Manolakopoulos ${ }^{2,4}$, Christos Triantos ${ }^{3}$, Christos Tsoulas ${ }^{6}$, George V Papatheodoridis ${ }^{2}$ and Ioannis Goulis $^{1 *}$ \\ ${ }^{1}$ Fourth Department of Internal Medicine, Hippocration University Hospital of Thessaloniki, Medical School of Aristotle University, Thessaloniki, Greece \\ ${ }^{2}$ Department of Gastroenterology, General Hospital of Athens "Laiko", Medical School of National \& Kapodistrian University of Athens, Greece \\ ${ }^{3}$ Division of Gastroenterology, Department of Internal Medicine, University Hospital of Patras, Medical School of Patras, Greece \\ ${ }^{4}$ Gastroenterology \& Endoscopy Unit, 2nd Department of Internal Medicine, Hippocration University Hospital of Athens, Medical School of National \& \\ Kapodistrian University of Athens, Greece \\ ${ }^{5}$ Gastroenterology \& Hepatology Department, University Hospital of Heraklion, Crete, Greece \\ ${ }^{6}$ Medical Department, Gilead Sciences Hellas, Greece
}

\begin{abstract}
Background: Epidemiology of NAFLD in Greece is largely unknown. Aim of this study was to record special epidemiological characteristics of NAFLD patients in Greece, to evaluate the histological severity of the disease and to assess the diagnostic performance of non-invasive methods for identifying advanced hepatic fibrosis.

Methods: Databases from five major liver centres in Greek tertiary hospitals were used to retrospectively record demographics, biochemistry, and histology from consecutive Greek NAFLD patients between mid-2018 and end-2019. The following highly validated, non-invasive methods were assessed: liver stiffness measurement (LSM) with Fibroscan ${ }^{\circledR}$, NAFLD Fibrosis score (NFS), FIB-4, AST to platelet ratio index (APRI), AST/ALT ratio, BARD score. The diagnostic accuracy was assessed statistically with areas under the receiver operating characteristic (AUROC).

Results: A total of 1,059 NAFLD patients were analysed, including 698 (65.9\%) with non-alcoholic steatohepatitis (NASH) and 106 (10\%) with NASH-related cirrhosis. Baseline patient characteristics: males 535 (50.6\%), mean age 59.5 \pm 14.1 years, median follow-up 9 years, $75.2 \%$ urban residents. Metabolic factors: mean BMI $30.1 \pm 4.7 \mathrm{~kg} / \mathrm{m}^{2}$, type 2 diabetes mellitus 22\%, dyslipidaemia 58.4\%. "Definite NASH" defined histologically by the NAFLD Activity Score was recorded in only $46.6 \%$ of patients undergoing liver biopsy. Best predictors for advanced fibrosis were LSM, NFS and FIB-4 with AUROC 0.897 (95\%CI 0.835-0.959, p<0.001), 0.867 (95\%CI 0.809-0.925, p<0.001), and 0.894 (95\%CI 0.844-0.944, p<0.001), respectively.
\end{abstract}

Conclusion: NAFLD patients in this cohort were middle-aged, overweight, with mild non-alcoholic steatohepatitis. Non-invasive methods, both Fibroscan ${ }^{\circledR}$ and NFS or FIB-4 scores, proved reliable tools for the identification of advanced hepatic fibrosis.

\section{Introduction}

Nonalcoholic fatty liver disease (NAFLD) affects almost $25 \%$ of the general population worldwide; it is currently the most prevalent chronic liver disease and is expected to continue rising in the upcoming decades [1-3]. Due to its well-established close association with the metabolic syndrome, it is estimated to be present in most individuals with obesity and type 2 diabetes mellitus (T2DM) [4-6]. Regarding the natural history and prognosis of the disease, it is widely accepted that NAFLD is mainly defined by its distinct histopathological stage which may range from simple nonalcoholic fatty liver (NAFL) to nonalcoholic steatohepatitis (NASH) and, ultimately, to NASH-related cirrhosis $[1,2,7]$.

Prevalence and incidence of NAFLD in Greece is largely unknown. However, it is estimated that NAFLD prevalence exceeds $30 \%$ of the general population, and that NASH may be present in up to $40 \%$ of NAFLD case-series [8,9]. In a previous epidemiological study we performed in Greek blood donors in an otherwise young and healthy population -, NAFLD was suspected in greater than $15 \%$ of all participants [10]. Furthermore, recent reports suggest that this metabolic disease is continually increasing in Greece, along with obesity and T2DM [11-13]. Finally, NAFLD has been characterized as a prominent risk factor for cirrhosis and hepatocellular carcinoma in the Greek population [14-15].

In the absence of effective treatments, the large number of NAFLD patients with potential for progressive liver disease creates challenges for population-based screening [2]. Several, high-validated, noninvasive tools have been developed in order to identify NAFLD patients at higher risk by predicting presence of advanced fibrosis, the major determinant for hepatic and extra-hepatic prognosis of the disease [1618]. Hepatic transient elastography [19-21]. and noninvasive scores of combined clinical-biochemical markers [22-25]. like the NAFLD

${ }^{\star}$ Correspondence to: Ioannis Goulis, Fourth Department of Internal Medicine, Hippocration University Hospital of Thessaloniki, 49 Konstantinopoleos Street, Greece, Tel: ++302310892040, 00306977774301, E-mail: igoulis@gmail.com

Key words: non-alcoholic fatty liver disease; non-alcoholic steatohepatitis; liver stiffness; non-invasive scores; fibrosis

Received: August 03, 2020; Accepted: August 17, 2020; Published: August 20 2020 
Fibrosis Score (NFS) and Fibrosis-4 (FIB-4), have been proved useful for this purpose $[26,27]$.

The aim of this study was to examine the epidemiology and severity of NAFLD patients seen in Greek tertiary liver centers, as well as to monitor current clinical practice with special reference to the performance of noninvasive tools in predicting advanced fibrosis.

\section{Patients and methods}

\section{Study population}

Databases from five major expert hepatology centers of Greek tertiary hospitals (two in Athens, and one in Thessaloniki, Patras and Heraklion Crete) were used to record consecutive patients diagnosed with NAFLD during the study period (June 2018 - December 2019). Diagnosis of NAFLD was based on current practice guidelines [27].

Inclusion criteria were age above 18 years-old, while exclusion criteria were all other causes of acute or chronic liver disease, severe comorbid conditions (end-stage renal disease, malignancy or metastatic cancer, chronic heart failure), history of excess (=above $140 \mathrm{~g} /$ week) alcohol consumption, probable drug-induced fatty liver (corticosteroids, amiodarone, valproic, tamoxifen etc.) and secondary fatty liver due to HIV, celiac disease, inflammatory bowel, pregnancy, etc.
Eligible patients were thereafter classified according to the clinical or histopathological diagnostic criteria defined in the TARGETNASH clinical study [28]. Briefly, NAFLD patients were grouped into NAFL (either evidence of liver steatosis on imaging but hepatic aminotransferases within normal or liver biopsy with hepatic steatosis without evidence of necro-inflammatory activity), NASH (either NAFL with elevated aminotransferases and presence of at least one metabolic factor - otherwise referred as "clinical NASH"- or histopathological evidence of steatohepatitis), and NASH-related cirrhosis (NASH with clinical or histopathological diagnosis of cirrhosis). Figure 1 presents the flow diagram for patient enrollment.

The study was approved by the Institutional Review Boards of each hospital, as well as the Bioethics Committee of the Medical School of Aristotle University, Thessaloniki, Greece. The STROBE statement criteria were applied for reporting observational studies [29].

\section{Demographic and anthropometric variables}

Databases provided information regarding gender, age (at the time of enrollment and at first diagnosis), and place of residence (urban/ rural). All patients were white Caucasians in origin.

Anthropometric measurements included weight (in kg), height (in $\mathrm{cm}$ ), body-mass index (BMI, in $\mathrm{kg} / \mathrm{m}^{2}$ ), waist and hip circumference (in

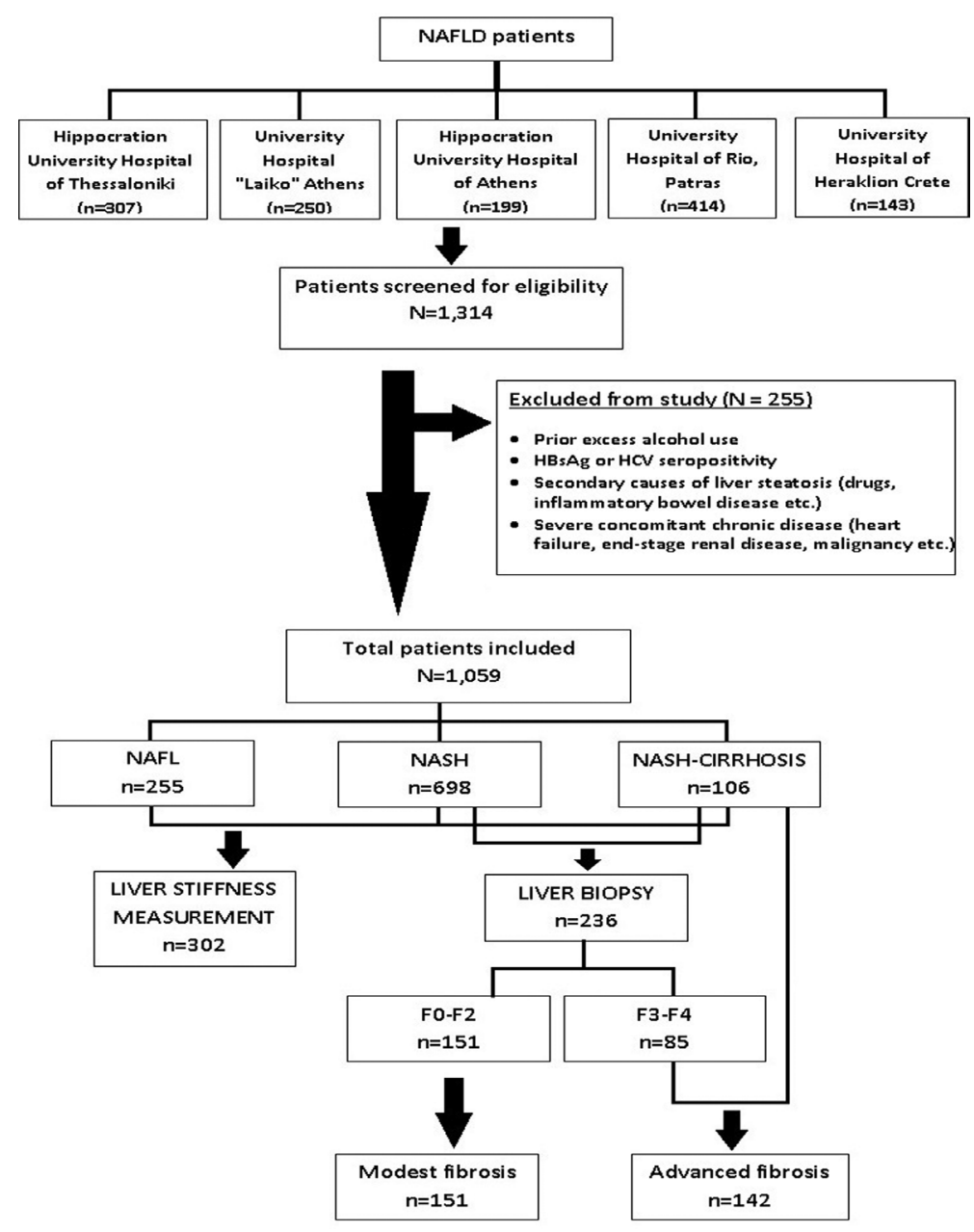

Figure 1. Flow chart demonstrating patient enrollment, screening and classification 
$\mathrm{cm}$ ) measured along the iliac crest and major trochanters, respectively, and waist to hip ratio (WHR). Patients were grouped into normal BMI $\left(<25 \mathrm{~kg} / \mathrm{m}^{2}\right)$, overweight $\left(25 \leq \mathrm{BMI}>30 \mathrm{~kg} / \mathrm{m}^{2}\right)$, obese $(30 \leq \mathrm{BMI}>40 \mathrm{~kg} /$ $\left.\mathrm{m}^{2}\right)$ and morbidly obese $\left(\mathrm{BMI} \geq 40 \mathrm{~kg} / \mathrm{m}^{2}\right)$.

Co-morbidities referred to factors of the metabolic syndrome, defined by an International Diabetes Federation consensus statement [30]. In specific, this consisted of the following five components:

(1) Central obesity, defined as waist circumference $\geq 94 \mathrm{~cm}$ for men and $\geq 80 \mathrm{~cm}$ for women.

(2) Impaired fasting glucose (IFG), defined as fasting plasma glucose $\geq 100 \mathrm{mg} / \mathrm{dL}$, or previously diagnosed T2DM.

(3) Raised serum triglycerides $>150 \mathrm{mg} / \mathrm{dL}$, or under treatment.

(4) Reduced high-density lipoprotein (HDL) cholesterol $<40 \mathrm{mg} / \mathrm{dL}$ for men and $<50 \mathrm{mg} / \mathrm{dL}$ for women, or under treatment.

(5) Raised blood pressure $\geq 130 \mathrm{mmHg}$ (systolic) or/and $\geq 85 \mathrm{mmHg}$ (diastolic), or under treatment of previously diagnosed hypertension.

Relevant to the metabolic impairment of insulin resistance, history of hypothyroidism was recorded in each patient, while occasional alcohol drinking, smoking habit, and exercise/physical activity was also investigated.

\section{Laboratory investigation and calculation of noninvasive scores}

Baseline laboratory evaluation included measurements by standard biochemical analyzers of alanine aminotransferase (ALT), aspartate aminotransferase (AST), and $\gamma$-glutamyl transpeptidase $(\gamma \mathrm{GT})$ in IU/L, platelet number (PLT), and albumin in $\mathrm{g} / \mathrm{dL}$, after 8-12 hour fasting, as appropriate. Upper limit of normal (ULN) for both aminotransferases was $35 \mathrm{IU} / \mathrm{L}$ for both males and females.

The following, easily obtainable, noninvasive scores, were calculated [23,24,31-36]: NFS, FIB-4, AST to PLT ratio index (APRI), BARD score and AST to ALT ratio. The following cut-offs (lower and upper limit reported for NFS and FIB-4) were used: NFS $<-1.455$ and $>0.676$; FIB- $4<1.3$ and $>2.67$; APRI $>0.88$; BARD $>2$; AST/ALT ratio $>0.8$, as suggested from previous studies [23-25, 33-35].

\section{Liver imaging}

Transient elastography was performed with the FibroScan ${ }^{\circ}$ medical device (Echosens, Paris France), using the standard (M) probe [19-21]. In each center, liver stiffness measurement (LSM) was assessed after an overnight fast, by trained experienced according to manufacturer's recommendations [37,38]. Cut-offs of $\leq 8 \mathrm{kPa}$ and of $>9.5 \mathrm{kPa}$ were used, as previously reported, to rule-out and rule-in advanced fibrosis, respectively $[21,25]$.

\section{Liver biopsy}

Needle liver biopsy data for a subgroup of NAFLD patients (Figure 1) was extracted from the medical files where available. Histologic examination had been performed by a "blinded" expert hepatopathologist, different at each centre, who had ruled out alternative diagnoses of chronic liver disease, confirmed and staged steatohepatitis.

Steatosis was semi-quantitatively assessed as the percentage of hepatocytes containing fat droplets and was graded as absent $(<5 \%$ of hepatocytes affected), mild or grade 1 (5\% to $33 \%)$, moderate or grade
2 (33\% to $66 \%)$ and severe or grade 3 ( $>66 \%$ ), according to the widely accepted Brunt's classification [39]. In addition to steatosis grade, type of steatosis predominance (macro-vesicular, micro-vesicular or mixed pattern) was assessed. Histological determination of necroinflammatory activity (including lobular inflammation and hepatocyte ballooning) was scored as mild, moderate or severe, and the NAFLD activity score (NAS) was calculated according to Kleiner et al. [40]. "Definite NASH" was defined as NASH $\geq 5$, while "borderline NASH" scored $2<\mathrm{NAS} \geq 4$, and "not NASH" had NAS $\leq 2$. Fibrosis was scored by the 5-point scale proposed by Brunt et al $[39,41]$. Briefly, this included $\mathrm{F} 0=$ absence of fibrosis; F1 = perisinusoidal fibrosis; F2 = perisinusoidal and portal/ periportal fibrosis; F3 = bridging fibrosis; F4 = cirrhosis. Fibrosis stages $\mathrm{F} 3$ and $\mathrm{F} 4$ were defined as stages of advanced fibrosis.

\section{Statistical analysis}

Continuous variables, depending on their distribution, were presented either as means \pm standard deviations or medians with $25^{\text {th }}-75^{\text {th }}$ IQR, while categorical variables as absolute numbers with respective percentage. Group comparisons were performed with $\chi^{2}$ test, one-way ANOVA or Kruskal-Wallis statistic, as indicated. Correlation was tested with Spearman's rho (rs) correlation coefficient.

Advanced fibrosis was addressed as the dependent (binary dichotomous) variable and was defined as presence of fibrosis stages F3-F4 (histological criterion) or presence of NASH-related cirrhosis (clinical criterion). (Figure 1). The accuracy of each score for detection of advanced fibrosis was assessed using the receiver operating characteristic (ROC) curves described as areas under ROC curve (AUROC) \pm standard error, accompanied by $95 \%$ confidence intervals (95\% CI) and statistical significance estimated by $\mathrm{p}$ values. Positive $(\mathrm{PPV})$ and negative predictive values (NPV) were finally calculated using standard, predefined, cut-off limits for each noninvasive diagnostic tool, as described above.

All statistical analyses were performed with SPSS 25. P-values less than 0.05 were considered statistically significant.

\section{Results}

\section{Baseline patient characteristics}

A total of 1,059 NAFLD patients were included in statistical analysis (Figure 1). Patients were grouped into NAFL $(n=255,24.1 \%)$, NASH $(\mathrm{n}=698,65.9 \%)$ and NASH-related cirrhosis $(\mathrm{n}=106,10 \%)$. Table 1 summarizes baseline patient characteristics, while Table 2 presents within group comparisons.

As presented in table 1, patients were approximately $50 \%$ males, middle-aged, and under follow-up for a median of 9 years. A small percentage of NAFLD patients had BMI within normal range (11.3\%), and only $22 \%$ of the study population had been diagnosed with IFG/ T2DM. Central obesity and dyslipidemia were the most frequent concomitant metabolic factors. Finally, approximately two thirds of the total study population consumed no alcohol nor smoked, and the majority abstained from occasional or regular exercise (81.1\%).

\section{Laboratory evaluations and non-invasive assessment of advanced fibrosis}

Laboratory investigation of liver biochemistry and calculation of various non-invasive scores are shown in table 2 . Statistically significant differences were recorded in the distribution of liver biochemistry, PLT and albumin concentration, as expected. The relationship between ALT, AST and $\gamma \mathrm{GT}$ is schematically demonstrated in figure 2 . 


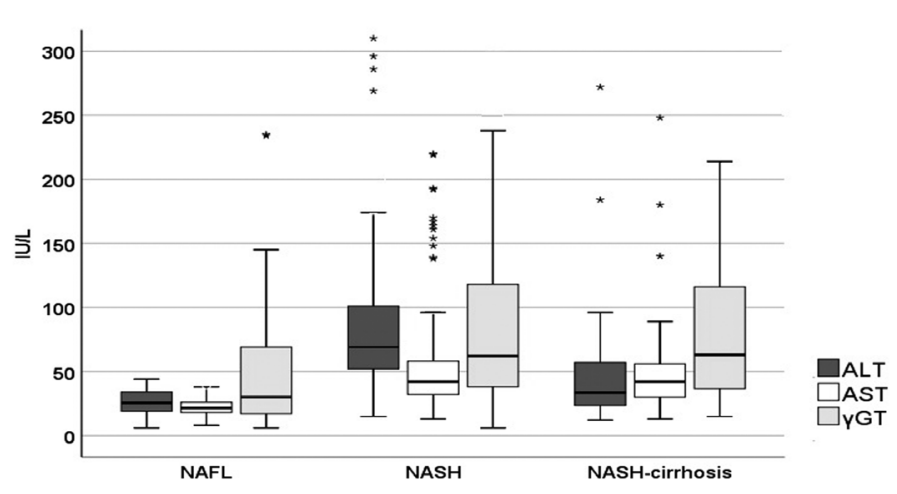

Figure 2. Distribution of liver enzymes in different NAFLD groups

Table 1. Baseline patient characteristics $\dagger$

\begin{tabular}{|c|c|}
\hline NAFLD REGISTRY (n=1, & \\
\hline Demographics & \\
\hline Gender & \\
\hline Male & $535(50.6 \%)$ \\
\hline Female & $524(49.4 \%)$ \\
\hline Age (years) & $59.5 \pm 14.1$ \\
\hline Age at $1^{\text {st }}$ diagnosis (years) & $51.1 \pm 14.1$ \\
\hline Follow-up (median, years) & $9(3-12)$ \\
\hline Residency & \\
\hline Rural & $234(24.8 \%)$ \\
\hline Urban & $709(75.2 \%)$ \\
\hline Anthropometrics & \\
\hline Weight $(\mathrm{kg})$ & $85.5 \pm 16.2$ \\
\hline Height $(\mathrm{cm})$ & $166.8 \pm 17.5$ \\
\hline BMI $\left(\mathrm{kg} / \mathrm{m}^{2}\right)$ & $30.1 \pm 4.7$ \\
\hline Normal BMI & $91(11.3 \%)$ \\
\hline Overweight & $332(41.1 \%)$ \\
\hline Obese & $358(44.3 \%)$ \\
\hline Morbidly obese & $27(3.3 \%)$ \\
\hline Waist (median, in cm) & $\begin{array}{l}\text { Males: } 104.5(98-112) \\
\text { Females: } 102(94-110)\end{array}$ \\
\hline Hip (median, in cm) & $106(99.5-113)$ \\
\hline Waist to Hip Ratio (median) & $0.97(0.92-1.05)$ \\
\hline Metabolic syndrome & \\
\hline Central obesity & $442(74.9 \%)$ \\
\hline Type 2 diabetes mellitus & $198(22 \%)$ \\
\hline Dyslipidemia & $513(58.4 \%)$ \\
\hline Hypertension & $264(29.5 \%)$ \\
\hline Hypothyroidism & $160(19.7 \%)$ \\
\hline Alcohol consumption ${ }^{\ddagger}$ & \\
\hline none & $534(63 \%)$ \\
\hline occasionally (<140g/week) & $313(37 \%)$ \\
\hline Smoking & \\
\hline no, never & $409(58.1 \%)$ \\
\hline current smoker & $177(25.1 \%)$ \\
\hline former smoker & $118(16.8 \%)$ \\
\hline Exercise/physical activity & \\
\hline limited & $331(81.1 \%)$ \\
\hline occasional & $50(12.3 \%)$ \\
\hline regular & $27(6.6 \%)$ \\
\hline $\begin{array}{l}\dagger \text { Table entries represent abso } \\
\text { deviations or medians with } 2 \\
\text { consumption exceeding the }\end{array}$ & $\begin{array}{l}\text { centage, means } \pm \text { standar } \\
\text { appropriate. } ¥ \text { Alcohol } \\
\text { in exclusion criteria }\end{array}$ \\
\hline
\end{tabular}

Table 2. Comparisons within NAFLD groups $\dagger$.

\begin{tabular}{|c|c|c|c|c|}
\hline & $\begin{array}{l}\text { NAFL } \\
(n=255)\end{array}$ & $\begin{array}{l}\text { NASH } \\
(n=698)\end{array}$ & $\begin{array}{l}\text { NASH-cirrhosis } \\
(\mathrm{n}=106)\end{array}$ & p values \\
\hline \multicolumn{5}{|l|}{ Demographics } \\
\hline Males & $107(42 \%)$ & $376(53.9 \%)$ & $52(49.1 \%)$ & 0.004 \\
\hline Age $^{\ddagger}$ (years) & $53 \pm 13.6$ & $48.6 \pm 13.7$ & $62.2 \pm 11.7$ & $<0.001$ \\
\hline \multicolumn{5}{|l|}{ Anthropometrics } \\
\hline BMI $\left(\mathrm{kg} / \mathrm{m}^{2}\right)$ & $29.7 \pm 4.7$ & $30 \pm 4.6$ & $32.5 \pm 5$ & 0.001 \\
\hline WHR & $0.96(0.91-1.03)$ & $0.99(0.94-1.46)$ & $1.02(0.95-1.10)$ & 0.039 \\
\hline \multicolumn{5}{|c|}{ Metabolic syndrome } \\
\hline Central obesity & $86(63.2 \%)$ & $308(79.6 \%)$ & $48(73.8 \%)$ & 0.001 \\
\hline T2DM & $29(17.4 \%)$ & $135(21.1 \%)$ & $34(36.6 \%)$ & 0.001 \\
\hline Dyslipidemia & $109(67.3 \%)$ & $374(59.8 \%)$ & $30(33 \%)$ & $<0.001$ \\
\hline Hypertension & $53(31.9 \%)$ & $185(29 \%)$ & $26(28.3 \%)$ & 0.735 \\
\hline Hypothyroidism & $31(20.1 \%)$ & $122(21 \%)$ & $7(9 \%)$ & 0.043 \\
\hline \multicolumn{5}{|l|}{ Habits } \\
\hline Alcohol & $57(33.1 \%)$ & $231(38.8 \%)$ & $25(31.3 \%)$ & 0.214 \\
\hline Smoking & $46(27.2 \%)$ & $121(24.5 \%)$ & $10(23.8 \%)$ & 0.856 \\
\hline Exercise & $7(7.4 \%)$ & $67(23.4 \%)$ & $3(11.1 \%)$ & 0.010 \\
\hline \multicolumn{5}{|c|}{ Laboratory evaluation } \\
\hline ALT (IU/L) & $27(20-35)$ & $69(52-101)$ & $33(23.5-54)$ & $<0.001$ \\
\hline AST (IU/L) & $22(18-26)$ & $43(32-59)$ & $42(30-57)$ & $<0.001$ \\
\hline$\gamma \mathrm{GT}(\mathrm{IU} / \mathrm{L})$ & $31.5(18-71)$ & $61(38-116)$ & $63(40.5-111.5)$ & $<0.001$ \\
\hline PLT (x109/L) & $248(214-285)$ & $232(198-267)$ & $125(89.5-153.5)$ & $<0.001$ \\
\hline Albumin $(\mathrm{g} / \mathrm{dL})$ & $4.7(4.5-4.9)$ & $4.6(4.3-4.8)$ & $3.5(2.7-4.2)$ & $<0.001$ \\
\hline \multicolumn{5}{|c|}{ Noninvasive scores of fibrosis } \\
\hline NFS & $\begin{array}{l}-1.337 \\
(-2.147--0.699)\end{array}$ & $\begin{array}{l}-1.588 \\
(-2.371--0.665)\end{array}$ & $\begin{array}{l}1.650 \\
(0.227-2.399)\end{array}$ & $<0.001$ \\
\hline FIB-4 & $\begin{array}{l}1.05 \\
(0.82-1.39)\end{array}$ & $\begin{array}{l}1.25 \\
(0.85-1.84)\end{array}$ & $\begin{array}{l}4.42 \\
(2.77-5.93)\end{array}$ & $<0.001$ \\
\hline APRI & $\begin{array}{l}0.25 \\
(0.21-0.32)\end{array}$ & $\begin{array}{l}0.53 \\
(0.37-0.79)\end{array}$ & $\begin{array}{l}1.02 \\
(0.69-1.41)\end{array}$ & $<0.001$ \\
\hline BARD $>2$ & $48(18.8 \%)$ & $253(36.2 \%)$ & $65(61.3 \%)$ & $<0.001$ \\
\hline AST/ALT ratio & $0.59(0.47-0.80)$ & $0.85(0.73-1.04)$ & $1.17(0.87-1.63)$ & $<0.001$ \\
\hline \multicolumn{5}{|c|}{ Imaging with Fibroscan ${ }^{\circledR}$} \\
\hline LSM $(\mathrm{kPa})$ & $6.0(4.8-7.3)$ & $6.9(5.5-9.8)$ & $21.2(15.7-25.7)$ & $<0.001$ \\
\hline \multicolumn{5}{|c|}{$\begin{array}{l}\text { †Table entries represent absolute numbers with respective percentage, means } \pm \text { standard } \\
\text { deviations or medians with } 25^{\text {th }}-75^{\text {th }} \text { interquartile range, as appropriate. Group } \\
\text { comparisons were performed with } \chi^{2} \text { test, one-way ANOVA or Kruskal-Wallis test, as } \\
\text { indicated. } \\
\text { ₹Age refers to patient age when diagnosis of NAFLD was first established, not at the time } \\
\text { of enrollment to the study. } \\
\text { Abbreviations stand for NAFL: nonalcoholic fatty liver; NASH: nonalcoholic } \\
\text { steatohepatitis; BMI: body-mass index; WHR: waist to hip ratio; T2DM: type } 2 \\
\text { diabetes mellitus; ALT: alanine aminotransferase; AST: aspartate aminotransferase; } \\
\gamma \text { GT: } \gamma \text {-glutamyl transpeptidase; PLT: platelets; NFS: NAFLD Fibrosis score; FIB-4: } \\
\text { Fibrosis-4 score; APRI: AST to platelet ratio; BARD: BMI-AST to ALT ratio-Diabetes; } \\
\text { LSM: Liver stiffness measurement. }\end{array}$} \\
\hline
\end{tabular}

Noninvasive scores and LSM were also found statistically different between groups $(\mathrm{p}<0.001)$. Interestingly, in the group of NASH-related cirrhosis, medians of all scores exceeded by far the upper cut-off limits adopted from the literature, as already described in the Methods section.

\section{Liver histology and liver stiffness measurements}

Data from 236 liver biopsies were recorded. This accounted for $22.3 \%$ of the total study population. As shown in figure 1, liver biopsy was not performed in the group of NAFL, and only to a subgroup of patients with NASH-related cirrhosis $(n=49)$, as many of the latter were considered to already have an established diagnosis of cirrhosis and/ or had contraindication for liver biopsy. Thus, histology was available in $31.6 \%$ of the remaining patient sample. As shown in table 3, the 
Table 3. Liver histology and liver stiffness measurements according to fibrosis stage. Abbreviations stand for NAS: NAFLD Activity score; IQR: interquartile range.

\begin{tabular}{|c|c|c|}
\hline \multicolumn{3}{|l|}{ Hepatic steatosis } \\
\hline None & $9(4.6 \%)$ & \\
\hline Grade 1 & $79(40.3 \%)$ & \\
\hline Grade 2 & $51(26 \%)$ & \\
\hline Grade 3 & $57(29.1 \%)$ & \\
\hline \multicolumn{3}{|l|}{ Steatosis type } \\
\hline Macro & $77(57 \%)$ & \\
\hline Micro & $13(9.6 \%)$ & \\
\hline Mixed & $45(33.3 \%)$ & \\
\hline \multicolumn{3}{|c|}{ Necro-inflammatory activity } \\
\hline None & $2(1.6 \%)$ & \\
\hline Mild & $69(53.5 \%)$ & \\
\hline Moderate & $55(42.6 \%)$ & \\
\hline Severe & $3(2.3 \%)$ & \\
\hline \multicolumn{3}{|l|}{ Hepatocyte ballooning } \\
\hline Absent & $32(21.6 \%)$ & \\
\hline Mild & $64(43.3 \%)$ & \\
\hline Marked & $52(35.1 \%)$ & \\
\hline NAS (median, IQR) & \multicolumn{2}{|l|}{$5(4-6)$} \\
\hline Not NASH (NAS 1-2) & \multicolumn{2}{|l|}{$22(14.9 \%)$} \\
\hline Borderline NASH & \multicolumn{2}{|l|}{$57(38.5 \%)$} \\
\hline Definite NASH (NAS $\geq 5$ ) & \multicolumn{2}{|l|}{$69(46.6 \%)$} \\
\hline \multicolumn{2}{|l|}{ Fibrosis stage } & $\begin{array}{l}\text { Liver stiffness (kPa) } \\
\text { (median, IQR) }\end{array}$ \\
\hline F0 & $32(13.6 \%)$ & $5.35(4.8-7)$ \\
\hline F1 & $69(29.2 \%)$ & $6.6(5.3-9.1)$ \\
\hline $\mathrm{F} 2$ & $50(21.2 \%)$ & $7.85(5.05-10.6)$ \\
\hline F3 & $36(15.3 \%)$ & $11.3(9.7-15.4)$ \\
\hline F4 & $49(20.8 \%)$ & $21.1(16.7-22)$ \\
\hline Total: & $236(100 \%)$ & $7.6(5.5-12.2)$ \\
\hline
\end{tabular}

majority of patients revealed findings of steatohepatitis with mild necroinflammatory activity, evident hepatic steatosis with predominant macro-vesicular pattern, and variable balanced distribution between different underlying stages of fibrosis (none to cirrhosis). Interestingly, evaluation of histological severity with NAS revealed that only $46.6 \%$ of patients had "definite NASH", while another $38.5 \%$ were "borderline NASH". These former patients accounted for the $90 \%$ of patients with grade 3 hepatic steatosis, the $100 \%$ of patients with severe lobular inflammation, and the $90 \%$ of patients with severe hepatocyte ballooning in liver biopsy (data not shown). Finally, NAS was found to correlate with fibrosis stage $(\mathrm{p}=0.017)$ and ALT value $(\mathrm{p}=0.006)$.

Finally, 302 liver stiffness recordings (28.5\% of total) were included and further analysed, as shown in table 2 and table 3 . This accounted for $45(17.6 \%)$ NAFL patients, $241(34.5 \%)$ NASH, and $16(15.1 \%)$ patients with NASH-related cirrhosis. Values ranged between 4.3 and $61.5 \mathrm{kPa}$. LSM was strongly associated with BMI; median liver stiffness was $5.3 \mathrm{kPa}$ for normal $\mathrm{BMI}(\mathrm{n}=26,28.6 \%)$ vs. $6.6 \mathrm{kPa}$ for overweight $(\mathrm{n}=96,28.9 \%)$ vs. $7.7 \mathrm{kPa}$ for obese $(\mathrm{n}=110,30.7 \%)$ vs. $10.4 \mathrm{kPa}$ for morbidly obese $(\mathrm{n}=5,18.5 \%)$ (Kruskal-Wallis test, $\mathrm{p}<0.001)$. A strong correlation was depicted between histological stage of fibrosis and liver stiffness measurements $\left(\mathrm{r}_{\mathrm{s}}=0.621, \mathrm{p}<0.001\right)$. Only 8 patients with NAFL $(17.8 \%)$ had LSM $>8 \mathrm{kPa}$, in contrast to $94(39 \%)$ patients with NASH and all patients with NASH-related cirrhosis. Finally, LSM correlated positively with all non-invasive scores (NFS, FIB-4, APRI, AST/ALT ratio, BARD score) with $\mathrm{p}<0.001$.

\section{Prediction of advanced fibrosis}

A total of 293 patients with NASH-related cirrhosis and histologically assessed clinical NASH (Figure 1) were used to test the performance of non-invasive tools. ROC curves are presented in figure 3 , in different panels because LSM was available in only 95 out of the 293 patients (32.6\%). AUROCs \pm standard errors for each non-invasive method were calculated:

- LSM: 0.897 \pm 0.032 (95\% CI 0.835-0.959), $\mathrm{p}<0.001$;

- NFS: $0.867 \pm 0.030$ (95\% CI 0.809-0.925), $\mathrm{p}<0.001$;

- FIB-4: 0.894 \pm 0.026 (95\% CI 0.844-0.944), $\mathrm{p}<0.001$;

- APRI: 0.775 \pm 0.036 (95\% CI 0.705-0.845), $\mathrm{p}<0.001$;

- BARD score: 0.724 \pm 0.041 (95\% CI 0.645-0.804), $\mathrm{p}<0.001$;

- AST/ALT ratio: 0.821 \pm 0.032 (95\% CI 0.758-0.884), $\mathrm{p}<0.001$.

The respective predictive values (PPV-NPV) were estimated by using previously reported cut-off limits as follows: LSM 64.3\%-93.3\%; NFS 85.1\%-91.1\%; FIB-4 92\%-92.3\%; APRI 72.8\%-68.6\%; BARD 66.7\%-69.9\%; AST/ALT ratio 75.9\%-73.7\%.

The application of upper and lower cut-off limits for LSM, NFS and FIB-4 classified a substantial proportion of patients (namely $8.4 \%, 33.3 \%$ and $35.2 \%$ of total) to the intermediate range of values. In continuum, while only $6.3 \%$ of patients with advanced fibrosis had values $8 \mathrm{kPa}<\mathrm{LSM} \geq 9.5 \mathrm{kPa}$ ), this percentage increased to $38.1 \%$ and $33.6 \%$ for the "grey zone" of NFS and FIB-4 respectively. On the other hand, if we relied solely on each one of these non-invasive methods, we would have avoided $92 \%, 67.5 \%$ and $61 \%$ of liver biopsies with a respective error (percentage of misclassified patients) of $19.3 \%, 8.2 \%$ and $6.7 \%$, respectively.

\section{Discussion}

This is the first large, multicentre, observational study in Greece which investigates the special epidemiological features of the country's NAFLD patients, as well as the performance of high-validated, easily obtainable, non-invasive methods in detecting advanced fibrosis.

As the global burden of NAFLD is rapidly rising [2] fatty liver and its sequelae have already replaced viral hepatitis as the mainstay of clinical hepatology worldwide, and referrals to specialists have risen more than double [42]. Even though the exact prevalence of the disease in Greece is largely unknown, it is estimated that NAFLD affects almost one third of modern Greeks [8,9] following the patterns encountered in the rest of the western world regarding the increasing trends of obesity and diabetes mellitus.

'Almost 3 out of 4 patients in this cohort had a diagnosis of NASH (almost 65\%) or NASH-related cirrhosis (10\%). These results probably overestimate the diagnosis of NASH in the Greek NAFLD population and may be explained by the fact that patients with abnormal liver enzymes and/or more advanced liver disease including cirrhosis are more likely to be referred to expert hepatology outpatients' clinics for further management, compared to simple liver steatosis on imaging alone.

NAFLD in our study-population affected both genders equally, with a mean age of diagnosis at 51 years-old, in line with previous reports [1]. The majority of NAFLD patients consumed no alcohol $(63 \%)$, neither did they smoke (58.1\%), while only a small minority $(6.6 \%)$ declared regular physical activity. Regarding the recorded prevalence of metabolic syndrome, NAFLD was largely linked to high BMI and central obesity; almost $90 \%$ of participants had an abnormal BMI and a large waist circumference exceeding $94 \mathrm{~cm}$ in men and $88 \mathrm{~cm}$ in 
women. On the other hand, presence of IFG or previously diagnosed T2DM was recorded in only $22 \%$ of our study population. This fact has to be addressed in future studies, as worldwide data reports pooled percentages ranging between $22.51 \%$ in all NAFLD and $43.63 \%$ in NASH patients $[1,26]$. However, an even lower prevalence of T2DM (14\%) has also been reported in another cohort of 162 Greek NAFLD patients [43]. One possible explanation is the overall management of patients with T2DM from diabetologists in Greece, and the lack of an established linkage between the two sub-specialties.

Older age, higher BMI and presence of T2DM -but not occasional alcohol consumption- were associated with presence of NASHrelated cirrhosis (Table 2). Alcohol is a key generating factor for fatty liver infiltration and progression to more advanced liver disease; unfortunately, the definition of significant alcohol consumption in published NAFLD literature has been inconsistent [26]. In this study we decided to define strict exclusion criteria regarding daily consumption or even past exposure to alcohol. Interestingly, we found that occasional alcohol drinking (less than $140 \mathrm{~g}$ per week for both men and women), compared to none, did not differ between different NAFLD groups, nor was it associated with the degree of liver fibrosis or liver stiffness (data not shown in detail). It has been proposed that low quantities of alcohol could lead to improved prognosis [26,44]. However, there are no longitudinal studies reporting the effect of ongoing alcohol consumption on disease severity or natural history of NAFLD/NASH, and the effects of light drinking on the cardiovascular system and cancer risks, if any, have not been investigated in individuals with NAFLD [26]. This issue has to be addressed in future studies.

Liver biopsy remains the gold standard for the diagnosis and staging of NAFLD. In this study we included data from 236 performed liver biopsies. Having excluded patients with NAFL $(n=255)$ and also a subgroup of patients with established NASH-related cirrhosis or patients contraindicated for liver biopsy $(\mathrm{n}=57)$, histology was available in almost one third of the remaining patient sample. As shown in Table 3, the majority, but not all, of patients considered to have NASH according to the TARGET-NASH study criteria had findings of steatohepatitis with mild activity and predominantly macro-vesicular steatotic pattern. Interestingly, "definite NASH" by histological criteria set by Kleiner et al. [40], was seen in almost half of the patients, while another $38.5 \%$ of patients scored at levels of "borderline NASH". This proportion has been met previously in larger cohorts of the NASH Clinical Research Network, where NAS $\geq 5$ was confirmed in $50 \%$ of 976 NASH adults [45]. and $61.9 \%$ of $446 \mathrm{NASH}$ patients entering clinical trials with therapeutic intervention [46]. However, as previously emphasized by Brunt et al. [47]. this histological classification of NASH regarding disease activity should not be misinterpreted, as the application of NAS is not supposed to be used as a surrogate for a diagnostic determination of NASH but rather to classify the relevant histological lesions. Finally, both fibrosis stage and level of ALT were found to positively correlate with NAS, as expected.

Regarding liver biopsy, it should be kept in mind, that it is an invasive method carrying a small but not negligible risk of complications $[23,48]$. Moreover, liver biopsy is either contra-indicated or denied by several patients. Sampling bias has also been reported in patients with NAFLD, that might affect both diagnosis and accurate staging of the disease [48]. Given these limitations, Fibroscan ${ }^{\circledR}$ has nowadays become an appealing alternative; however, its main limitation in clinical practice is its failure to obtain reliable measurements $(\sim 10-20 \%$ of cases, mainly obese patients when examined with the $\mathrm{M}$ probe), which restricts its application in NAFLD [22-37]. For this reason, criteria for reliable measurements have been determined $[37,38]$.
In our cohort of NAFLD patients, LSM was recorded in almost one third of patients. Liver stiffness was found to correlate excellent with histological fibrosis stage and also with different noninvasive scoring systems. Its correlation with BMI has to be interpreted with caution, given the fact that Fibroscan ${ }^{\circ}$ may overestimate liver stiffness in cases of excess visceral fat $[22,38]$. Nevertheless, its ability to predict advanced fibrosis was confirmed by an estimated AUROC of 0.897 , even though only 95 patients were analysed (Figure 3A). The low PPV of $64.3 \%$ could be explained by the selection of a rather low upper cutoff limit $(9.5 \mathrm{kPa})$, when other reports suggest cut-offs $>12-14 \mathrm{kPa}$ [37]. Furthermore, it should be kept in mind that increased BMI and WHR in our study population might have influenced measurements.

Apart from transient hepatic elastography, EASL guidelines for NAFLD management endorse NFS and FIB-4 as the most validated tools for the diagnosis of severe fibrosis in NAFLD, with reported AUROCs exceeding 0.8 for both [27]. We calculated some of the most easily obtainable scoring systems in our study population, namely NFS, FIB-4, APRI, BARD and AST/ALT ratio. Subsequently, we obtained AUROCs with respective $95 \% \mathrm{CI}$ and found impressively high accuracy in predicting advanced fibrosis (Figure 3B). Specifically, NFS and FIB-4 had both AUROCs up to 0.867 and 0.894 , respectively, while APRI, BARD and AST/ALT ratio did not perform the same, as previously described [23-25,34-36]. Interestingly, NFS was not found superior to the even more easily obtainable FIB-4. By applying well-described cut-off limits for both ruling-in and ruling-out advanced fibrosis, we estimated PPV and NPV, which proved to exceed $85 \%$ for NFS and FIB- 4 , while other values remained suboptimal, ranging from $66.7 \%$ to $75.9 \%$. In line with previous reports, NPV was greater than PPV for both NFS and FIB-4 [34,36].

Certainly, several limitations exist within this study. First, the retrospective nature of every observational study is prone to selection bias. Moreover, it has already been discussed earlier that, due to the referral of patients with abnormal liver enzymes, more advanced stages of NAFLD, namely NASH and NASH-related cirrhosis, have been recorded, with a misleading and underestimated percentage of NAFL. Furthermore, advanced fibrosis in our study was defined either by the gold standard of liver biopsy - bearing in mind referral bias for liver biopsy and sampling errors in histopathology findings or by clinical criteria. Liver biopsies were read by independent liver pathologists at each centre, and we were not able to quantify the effect of intra-observer and inter-observer variability in fibrosis staging. However, quantification of fibrosis in patients with NAFLD has the lowest intra-observer and inter-observer variability as compared to any other histological features [23]. In the same way, Fibroscan ${ }^{\circledR}$ was also performed by a different operator at each centre. All measurements were performed with the M probe, but not the XL probe which has been found more suitable in cases of obesity [49]. This was for reasons of homogeneity; not all centres had the opportunity to select between probes. However, all pre-defined reliability criteria for performed liver stiffness measurements had to be fulfilled as reported above, otherwise they were missing. This might explain the small percentage of assessment in morbidly obese patients in our study. Finally, we did not try to set different cut-offs, nor did we proceed to age-adjustments for NFS as proposed in the literature [50].

In conclusion and despite the limitations of this observational study, the results confirm high reliability of noninvasive assessment of liver fibrosis in Greek patients with NAFLD. Future prospective studies need to examine the effectiveness of noninvasive methods as screening tools in broad populations with high-risk for NAFLD such as patients with obesity and T2DM. 
A

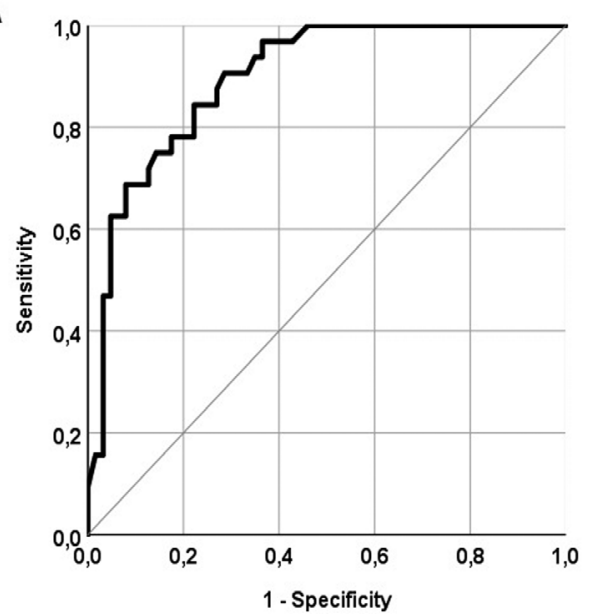

B

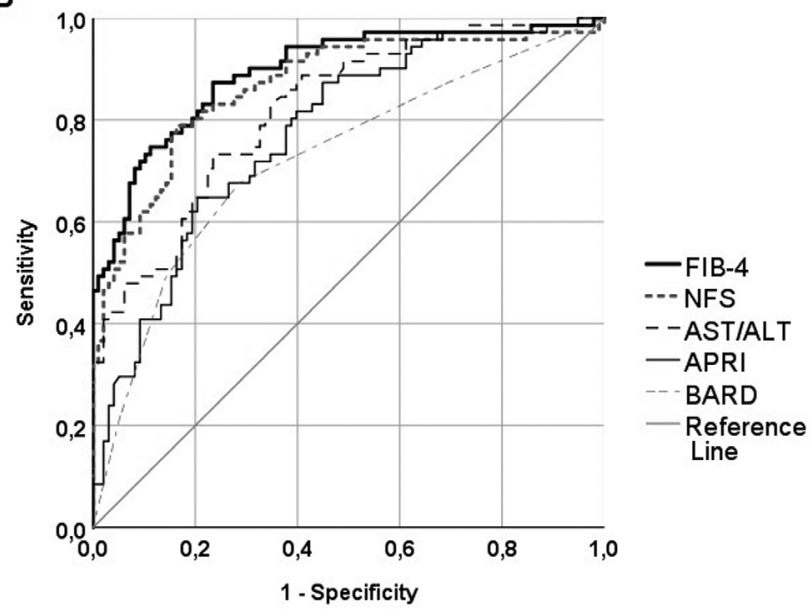

Figure 3. ROC curves for the prediction of advanced fibrosis assessing A. Liver stiffness measurement (LSM) with Fibroscan ${ }^{\circledR}$ B. Noninvasive scores of liver fibrosis.

\section{Summary box}

\section{What is already known:}

- Non-alcoholic fatty liver disease has become the most prevalent chronic liver disease worldwide and is expected to rise in the upcoming decades.

- The epidemiology of the disease is largely unknown in Greece, although sporadic reports reveal increasing prevalence rates.

- Even though liver biopsy remains the golden standard for diagnosis and staging of the disease, non-invasive methods like transient hepatic elastography and non-invasive scoring systems have been proved reliable tools in identifying advanced hepatic fibrosis; however, their diagnostic performance has never been tested in the Greek population.

\section{New findings}

- This is the first multicentre observational study in Greece that reports the special epidemiological characteristics of NAFLD patients followed-up in Greek tertiary liver centres.

- The majority of NAFLD patients in this cohort were middle-aged, overweight or obese patients with histologically findings of mild non-alcoholic steatohepatitis.

- FibroScan ${ }^{\oplus}$, NAFLD Fibrosis Score (NFS) and Fibrosis-4 (FIB4) presented high diagnostic accuracy in ruling-out and ruling-in advanced hepatic fibrosis.

\section{Acknowledgments}

The study was conducted under the supervision of the Medical School of Aristotle University of Thessaloniki Greece as part of a postdoctorial thesis by Dr. Savvidou.

\section{References}

1. Younossi ZM, Koenig AB, Abdelatif D, Fazel Y, Henry L, et al. (2016) Global epidemiology of nonalcoholic fatty liver disease-Meta-analytic assessment of prevalence, incidence, and outcomes. Hepatology 64: 73-84. [Crossref]

2. Younossi Z, Anstee QM, Marietti M, Hardy T, Henry L, et al. (2018) Global burden of NAFLD and NASH: trends, predictions, risk factors and prevention. Nat Rev Gastroenterol Hepatol 15: 11-20. [Crossref]
3. Estes C, Anstee QM, Arias-Loste MT, Bantel H, Bellentani S, et al. (2018) Modeling NAFLD disease burden in China, France, Germany, Italy, Japan, Spain, United Kingdom, and United States for the period 2016-2030. J Hepatol 69: 896-904. [Crossref]

4. Cusi K (2012) Role of obesity and lipotoxicity in the development of nonalcoholic steatohepatitis: pathophysiology and clinical implications. Gastroenterol 142: 711-725.

5. Cusi K (2009) Role of insulin resistance and lipotoxicity in non-alcoholic steatohepatitis Clin Liver Dis 13: 545-563.

6. Younossi ZM, Golabi P, de Avila L, Paik JM, Srishord M, et al. (2019) The global epidemiology of NAFLD and NASH in patients with type 2 diabetes: A systematic review and meta-analysis. J Hepatol 71: 793-801. [Crossref]

7. Adams LA, Sanderson S, Lindor KD, Angulo P (2005) The histological course of nonalcoholic fatty liver disease: a longitudinal study of 103 patients with sequential liver biopsies. J Hepatol 42: 132-138.

8. Sherif ZA, Saeed A, Ghavimi S, Nouraie SM, Laiyemo AO, et al. (2016) Global Epidemiology of Nonalcoholic Fatty Liver Disease and Perspectives on US Minority Populations. Dig Dis Sci 61: 1214-1225. [Crossref]

9. Zois CD, Baltayiannis GH, Bekiari A, Goussia A, Karayiannis P, et al. (2010) Steatosis and steatohepatitis in postmortem material from Northwestern Greece. World $J$ Gastroenterol 16: 3944-3949. [Crossref]

10. Papatheodoridis GV, Goulis J, Christodoulou D, Manolakopoulos S, Raptopoulou M et al. (2007) High prevalence of elevated liver enzymes in blood donors: associations with male gender and central adiposity. Eur J Gastroenterol Hepatol 19: 281-287. [Crossref]

11. Ng M, Fleming T, Robinson M (2014) Global, regional, and national prevalence of overweight and obesity in children and adults during 1980-2013: a systematic analysis for the Global Burden of Disease Study 2013. Lancet 384: 766-781.

12. Ricci G, Tomassoni D, Pirillo I, Sirignano A, Sciotti M, et al. (2018) Obesity in the European region: social aspects, epidemiology and preventive strategies. Eur Rev Med Pharmacol Sci 22: 6930-6939. [Crossref]

13. Cho NH, Shaw JE, Karuranga S, Huang Y, da Rocha Fernandes JD, Ohlrogge AW, et al. (2018) IDF Diabetes Atlas: Global estimates of diabetes prevalence for 2017 and projections for 2045. Diabetes Res Clin Pract 138: 271-281. [Crossref]

14. Giannousis IP, Papatheodoridis GV, Deutsch MJ, Manolakopoulos SG, Manesis EK et al. (2010) The burden and recent epidemiological changes of the main chronic liver diseases in a Greek referral tertiary centre. Eur J Gastroenterol Hepatol 22: 172-179. [Crossref]

15. Karageorgos SA, Stratakou S, Koulentaki M, Voumvouraki A, Mantaka A, et al (2017) Long-term change in incidence and risk factors of cirrhosis and hepatocellular carcinoma in Crete, Greece: a 25-year study. Ann Gastroenterol 30: 357-363. [Crossref]

16. Angulo P, Kleiner DE, Dam-Larsen S, Adams LA, Bjornsson ES, et al. (2015) Liver fibrosis, but no other histologic features, is associated with long-term outcomes of patients with nonalcoholic fatty liver disease. Gastroenterol 149: 389-397. [Crossref] 
17. Dulai PS, Singh S, Patel J, Soni M, Prokop LJ, et al. (2017) Increased risk of mortality by fibrosis stage in non-alcoholic fatty liver disease: Systematic review and metaanalysis. Hepatology 65: 1557-1565. [Crossref]

18. Ekstedt M, Hagström H, Nasr P, Fredrikson M, Stål P, et al. (2015) Fibrosis stage is the strongest predictor for disease-specific mortality in NAFLD after up to 33 years of follow-up. Hepatology 61: 1547-1554.

19. Sandrin L, Fourquet B, Hasquenoph JM, Yon S, Fournier C, et al. (2003) Transient elastography: a new noninvasive method for assessment of hepatic fibrosis. Ultrasound Med Biol 29: 1705-1713. [Crossref]

20. Bonder A, Afdhal N (2014) Utilization of FibroScan in Clinical Practice. Curr Gastroenterol Rep 16: 372 .

21. Wong VW, Vergniol J, Wong GL, Foucher J, Lik-Yuen Chan H, et al. (2010) Diagnosis of fibrosis and cirrhosis using liver stiffness measurement in nonalcoholic fatty liver disease. Hepatology 51: 454-462. [Crossref]

22. Castera L, Vilgrain V, Angulo P (2013) Noninvasive evaluation of NAFLD. Nat Rev Gastroenterol Hepatol 10: 666-675. [Crossref]

23. Angulo P, Hui JM, Marchesini G, Bugianesi E, George J, et al. (2007) The NAFLD fibrosis score: a noninvasive system that identifies liver fibrosis in patients with NAFLD. Hepatology 45: 846-854. [Crossref]

24. McPherson S, Stewart SF, Henderson E, Burt AD, Day CP (2010) Simple noninvasive fibrosis scoring systems can reliably exclude advanced fibrosis in patients with nonalcoholic fatty liver disease. Gut 59: 1265-1269.

25. Petta S, Wong VW, Cammà C, Hiriart JB, Wong GLH, et al. (2017) Serial combination of noninvasive tools improves the diagnostic accuracy of severe liver fibrosis in patients with NAFLD. Aliment Pharmacol Ther 46: 617-627. [Crossref]

26. Chalasani N, Younossi Z, Lavine JE, Charlton M, Cusi K, et al. (2018) The diagnosis and management of non-alcoholic fatty liver disease: Practice guidance from the American Association for the Study of Liver Diseases. Hepatology 67: 328-357. [Crossref]

27. European Association for the Study of the Liver (EASL); European Association for the Study of Diabetes (EASD); European Association for the Study of Obesity (EASO) (2016) EASL-EASD-EASO Clinical Practice Guidelines for the management of nonalcoholic fatty liver disease. J Hepatol 64: 1388-1402.

28. Barritt AS, Gitlin N, Klein S, Lok AS, Loomba R, et al. (2017) Design and rationale for a real-world observational cohort of patients with nonalcoholic fatty liver disease: The TARGET-NASH study. Contemp Clin Trials 61: 33-38. [Crossref]

29. vonElm E, Altman DG, Egger M, Pocock SJ, Gøtzsche PC, et al. (2014) The Strengthening the Reporting of Observational Studies in Epidemiology (STROBE) Statement: guidelines for reporting observational studies. Int J Surg 12: 1495-1499. [Crossref]

30. Alberti KG, Zimmet P, Shaw J. (2006) Metabolic syndrome--a new world-wide definition. A Consensus Statement from the International Diabetes Federation. Diabet Med 23: 469-480

31. Wai CT, Greenson JK, Fontana RJ, Kalbfleisch JD, Marrero JA, et al. (2003) A simple non invasive index can predict both significant fibrosis and cirrhosis in patients with chronic hepatitis C. Hepatology 38: 518-526. [Crossref]

32. Loaeza-del-Castillo A, Paz-Pineda F, Oviedo-Cárdenas E, Sánchez-Avila F, VargasVorácková F (2008) AST to platelet ratio index (APRI) for the noninvasive evaluation of liver fibrosis. Ann Hepatol 7: 350-357.

33. Harrison SA, Oliver D, Arnold HL, Gogia S, Neuschwander-Tetri BA (2008) Development and validation of a simple NAFLD clinical scoring system for identifying patients without advanced disease. Gut 57: 1441-1447. [Crossref]
34. Ruffillo G, Fassio E, Alvarez E, Landeira G, Longo C, et al. (2011) Comparison of NAFLD fibrosis score and BARD score in predicting fibrosis in nonalcoholic fatty liver disease. J Hepatol 54: 160-163. [Crossref]

35. Ohgo H, Yokoyama H, Hirose H, Kawabe H, Saito I, et al. (2009) Significance of ALT/ AST ratio for specifying subjects with metabolic syndrome in its silent stage. Diabetes Metab Syndr Clin Res Rev 3: 3-6.

36. Kaswala DH, Lai M, Afdhal NH (2016) Fibrosis assessment in nonalcoholic fatty liver disease (NAFLD) in 2016. Dig Dis Sci 61: 1356-1364.

37. Castera L, Foucher J, Bernard PH, Carvalho F, Allaix D, et al. (2010) Pitfalls of liver stiffness measurement: a 5-year prospective study of 13,369 examinations. Hepatology 51: 828-835. [Crossref]

38. Boursier J, Zarski JP, deLedinghen V, Rousselet MC, Sturm N, et al. (2013) Multicentric Group from ANRS/HC/EP23 FIBROSTAR Studies. Determination of reliability criteria for liver stiffness evaluation by transient elastography. Hepatology 57: 1182-1191. [Crossref]

39. Brunt EM, Janney CG, Di Bisceglie AM, Neuschwander-Tetri BA, Bacon BR (1999) Nonalcoholic steatohepatitis: a proposal for grading and staging the histological lesions. Am J Gastroenterol 94: 2467-2474.

40. Kleiner DE, Brunt EM, Van Natta M, Behling C, Contos MJ, et al. (2005) Nonalcoholic steatohepatitis clinical research network. Design and validation of a histological scoring system for nonalcoholic fatty liver disease. Hepatology 41: 1313-1321. [Crossref]

41. Brunt EM (2001) Nonalcoholic Steatohepatitis: Definition and Pathology. Semin Liver Dis 21: 3-16.

42. George J, Anstee Q, Ratziu V, Sanyal A (2018) NAFLD: The evolving landscape. $J$ Hepatol 68: 227-229.

43. Margariti E, Deutsch M, Manolakopoulos S, Papatheodoridis GV (2012) Nonalcoholic fatty liver disease may develop in individuals with normal body mass index. Ann Gastroenterol 25: 45-51.

44. Dunn W, Sanyal AJ, Brunt EM, Unalp-Arida A, Donohue M, et al. (2012) Modest alcohol consumption is associated with decreased prevalence of steatohepatitis in patients with non-alcoholic fatty liver disease (NAFLD). J Hepatol 57: 384-391. [Crossref]

45. Brunt EM, Kleiner DE, Wilson LA, Belt P, Neuschwander-Tetri BA (2011) Nonalcoholic fatty liver disease (NAFLD) activity score and the histopathologic diagnosis in NAFLD: Dinstinct clinicopathologic meanings. Hepatology 53: 810-820.

46. Kleiner DE, Brunt EM, Wilson LA, Behling C, Guy C, et al. (2019) Association of histologic disease activity with progression of non-alcoholic fatty liver disease. JAMA Network Open 2: e1912565. [Crossref]

47. Brunt EM, Kleiner DE, Behling C, Contos MJ, Cummings OW, et al. (2011) Misuse of scoring systems. Hepatology 54: 370-371. [Crossref]

48. Papagianni M, Sofogianni A, Tziomalos K (2015) Noninvasive methods for the diagnosis of nonalcoholic fatty liver disease. World J Hepatol 7: 638-648.

49. de Lédinghen V, Vergniol J, Foucher J, El-Hajbi F, Merrouche W, et al. (2010) Feasibility of liver transient elastography with FibroScan using a new probe for obese patients. Liver Int 30: 1043-1048. [Crossref]

50. McPherson S, Hardy T, Dufour JF, Petta S, Romero-Gomez M, et al. (2017) Age as a confounding factor for the accurate noninvasive diagnosis of advanced NAFLD fibrosis. Am J Gastroenterol 112: 740-775. [Crossref]

Copyright: (C2020 Savvidou S. This is an open-access article distributed under the terms of the Creative Commons Attribution License, which permits unrestricted use, distribution, and reproduction in any medium, provided the original author and source are credited. 